Research Article

\title{
Characteristic Features of Electric Fields Radiated by Cloud Flashes in Himalayan Region
}

\author{
Pitri Bhakta Adhikari $\mathbb{D}^{1,2}$ and Shriram Sharma ${ }^{3}$ \\ ${ }^{1}$ Department of Physics, Tri-Chandra Campus, Tribhuvan University, Kirtipur, Nepal \\ ${ }^{2}$ Central Department of Physics, Tribhuvan University, Kirtipur, Nepal \\ ${ }^{3}$ Department of Physics, Amrit Science Campus, Tribhuvan University, Kirtipur, Nepal \\ Correspondence should be addressed to Pitri Bhakta Adhikari; pbadhikari09@gmail.com
}

Received 21 September 2019; Revised 15 November 2019; Accepted 26 November 2019; Published 10 January 2020

Academic Editor: Ping Li

Copyright (c) 2020 Pitri Bhakta Adhikari and Shriram Sharma. This is an open access article distributed under the Creative Commons Attribution License, which permits unrestricted use, distribution, and reproduction in any medium, provided the original work is properly cited.

\begin{abstract}
Electric fields radiated by cloud flashes that occurred over the rugged terrain of mountainous country Nepal were recorded, analysed, and compared with those from different geographical regions. The total duration of the flash varies from 80 to $469.5 \mathrm{~ms}$. The majority of the cloud flashes were of two stages: the first stage of the majority of the flashes was found to consist of large microsecond scale bipolar pulses having negative initial polarity and the late stage consists of submicrosecond scale pulses having both positive and negative initial polarities. The average durations of the first and second stages are 11.23 and $66.79 \mathrm{~ms}$, respectively, and the time gap between them is $53.57 \mathrm{~ms}$. The cloud pulses led by the negative initial polarity pulses are more compactly distributed and are higher in mountainous countries as compared to those of flashes lead by positive initial polarity pulses, with the average values of interpulse interval being 211.42 and $309.79 \mu$ s, respectively.
\end{abstract}

\section{Introduction}

Lightning discharges, which do not connect to the earth's surface, are called cloud flashes. These include intracloud, intercloud, and air discharges. However, intracloud discharges occur frequently among these flashes. Although about three-quarters of the total lightning discharges are believed to be cloud discharges, they have received much less attention and hence are less well understood compared to the ground flashes. The main reason behind this obviously is that they do not pose any threat to life on earth. Likewise, difficulty in obtaining measurements on cloud flashes is another reason for having less information. However, cloud flashes should not be underestimated because of the threat on avionics and electromagnetic devices. Furthermore, the study of cloud flashes is as important as the ground flashes to understand the physics of lightning discharge. Cloud flashes exhibit much variability from flash to flash and storm to storm, as they do not involve any well-defined conducting electrode, rather they are the electrodeless discharges [1].
Examples of cloud flashes showing variability from flash to flash are depicted in Figure 1. Rakov and Uman [1] have further explained that the upper and lower boundaries of a negative charge region are the most likely places for the cloud flash to begin, and it is thought that the cloud flashes often bridge the main negative and upper positive charge regions. The majority of the cloud flashes exhibit the twostage model with the initial stage being active stage corresponding to the initial breakdown stage with large microsecond scale bipolar pulses resulting in a large slow field variation. The initial polarity of the breakdown pulses can be of both positive and negative type; among them, the flashes led by the initial breakdown (IB) pulses with positive initial polarity are more common.

Kitagawa and Brook [2] classified the cloud flashes in three stages, namely, initial, very active, and final stages. However, Bils et al. [3] and Villanueva et al. [4] showed that the cloud flashes are composed of two stages. The initial stage (or the most active stage) and the final stage, which are similar to that reported by Kitagawa and Brook [2], 


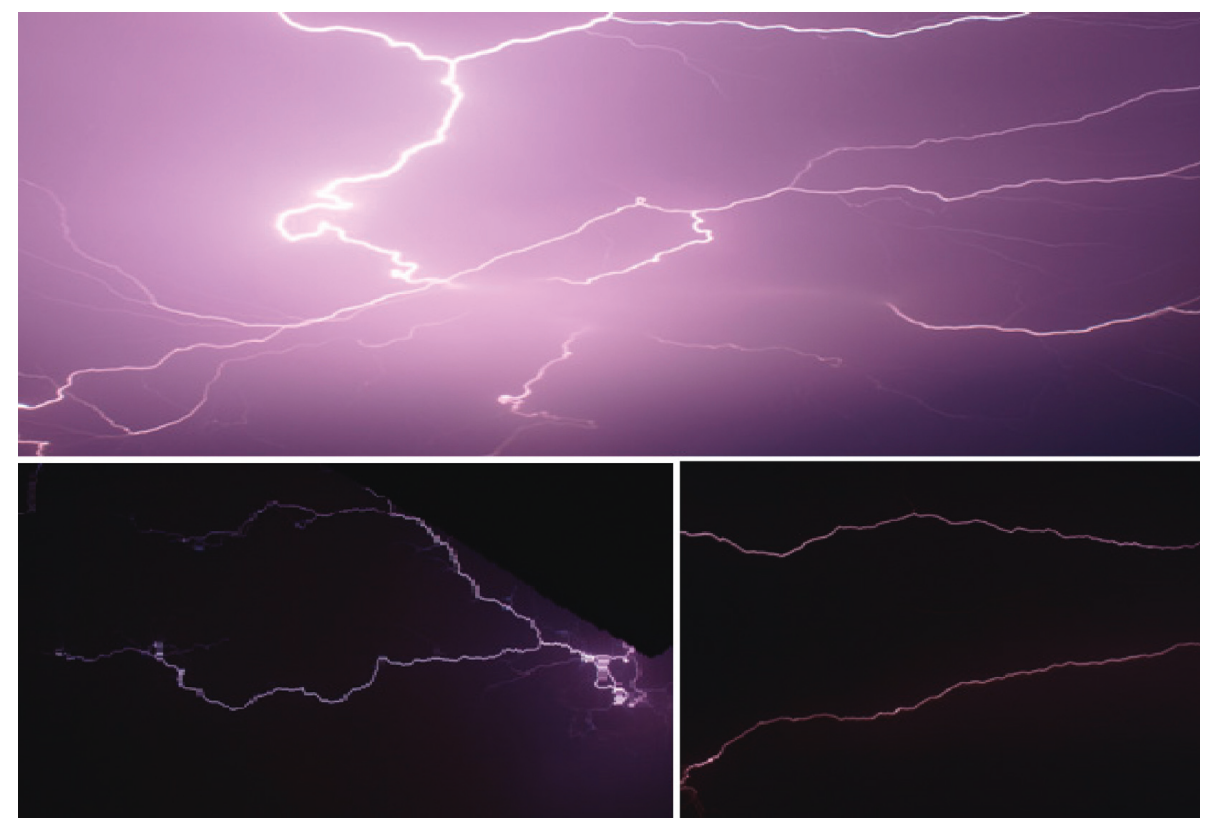

FIgURE 1: Example of cloud flashes showing variability from flash to flash.

consisted of sequences of $K$ changes. Villanueva et al. [4] not only from their own data but also from the original data of Kitagawa and Brook [2] have concluded that the cloud flashes involve only the two-stage model. According to Shao and Krehbiel [5], the cloud discharges often exhibit a single vertical channel that bridges the lower-level and upper-level charge regions in the cloud. Rison et al. [6] in agreement with Shao and Krehbiel [5] reported that most of the radiation sources were located at the upper-level. However, it is quite apparent that the cloud flashes can also take place between the main negative charge region and the lower positive charge pocket. Proctor [7] and Proctor [8] reported that VHF and UHF pulses in higher-origin flashes are radiated at a lower rate as compared to that in lower-origin flashes. Proctor [8] further reported that the lower-origin cloud flashes are indistinguishable from the stepped leaders in the cloud to ground flashes.

Gomes et al. [9] conducted a comprehensive study on chaotic pulse trains (CPT) and described the initial polarity, pulse width, pulse separation, and pulse amplitude of CPTs. The pulse width was distributed between 1 and $10 \mu$ s with a high probability of $2-4 \mu$ s and the pulse separation lies in the range of 2-20 $\mu \mathrm{s}$. Shriram [10] explained the tripole structure of the charges in which a lightning discharge has a long channel with many branches that extend up to several kilometers vertically as well as horizontally. Similarly, the discharge from the main negative charge centre to the upper positive charge centre gives positive electric field change and the discharge from the main negative charge centre to the lower positive charge pocket gives negative electric field changes as shown in Figure 2. The occurrence of breakdown pulses with both polarities suggests that the breakdown apparently takes place either between the upper negative charge boundary and the positive charge region or between the lower negative charge boundary and the lower positive charge pocket. The discharge between the main negative charge boundary and the upper positive charge region can be regarded as higher-origin cloud flashes and that between lower negative charge boundary and lower positive charge pocket can be regarded as lower-origin flashes.

Weidman and Krider [11] analysed the intracloud lightning waveforms of the radiation fields and reported that the waveforms are alike within a discharge and differ with the return stroke of the cloud to ground lightning. Krider et al. [12] reported that the waveform of the radiation field pulse begins with a fast large amplitude portion followed by a small and slowly varying overshoot. In addition, the FWHM and the time interval between successive pulses (for the pulse train of $400 \mu \mathrm{s}$ ) were reported to be $0.75 \mu \mathrm{s}$ and $5 \mu \mathrm{s}$, respectively. Gomes and Cooray [13], on the other hand, reported that the time interval between the successive pulses for $50 \mathrm{~ms}$ pulse train to be $147 \mu \mathrm{s}$. They further reported that the pulses were of two types: multiply peaked pulses with less pronounced overshoot and single peaked pulses with a pronounced positive overshoot. There are three different types of pulses pertinent to the cloud flashes that have been observed and reported in the literature. Krider et al. [12] reported the sequences of unipolar pulses similar to those produced by dart-stepped leaders in discharge to earth; Weidman and Krider [11] have observed the bipolar pulses with structures on their fronts and Le Vine [14] and Cooray and Lundquist [15] have observed the bipolar pulses without such structures.

Nag and Rakov [16] examined the electric field pulse trains that are characteristics of the preliminary breakdown in the negative cloud to ground discharge and described that such pulse trains are manifestations of the initiation of downward negative stepped leaders that fail to propagate to the ground. According to Nag and Rakov [17] the excessive lower positive charge pocket in the tripole structure converts 


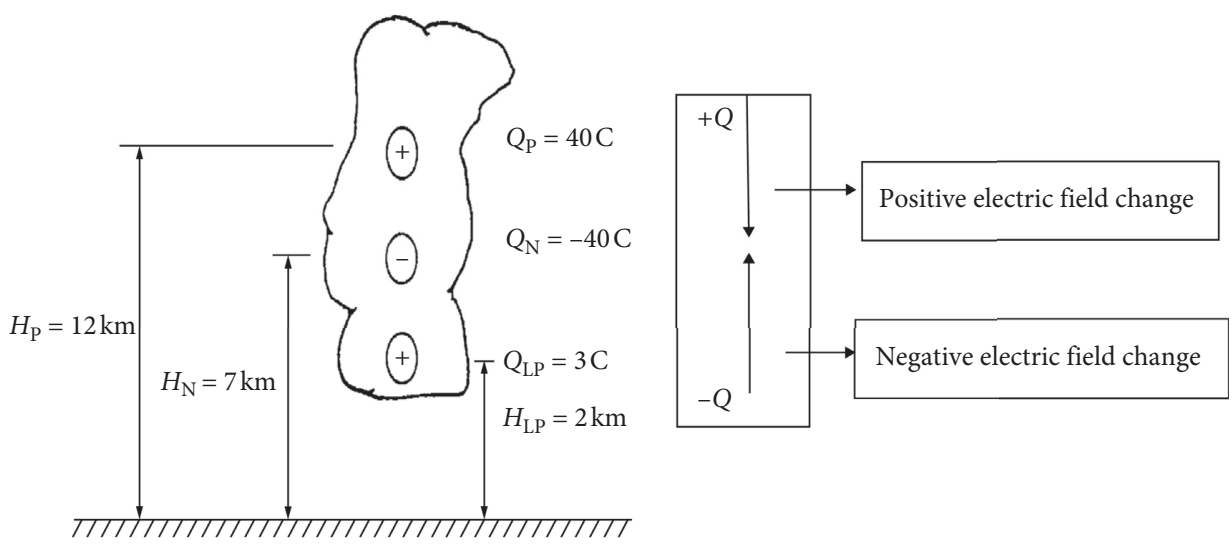

Figure 2: An idealized vertical tripole structure of a thunderstorm (adopted from [1]).

the cloud to ground flash to an intracloud one. Nag and Rakov [18] examined the various conceptual cloud charge configurations leading to the production of positive lightning discharges and found out that there were many disparities between positive and negative flashes in multiplicity, preliminary breakdown pulse trains, leader propagation mode, branching of the in-cloud channel, and occurrence of continuing currents.

The preliminary breakdown pulses have been realized by three-dimensional locating system by Bitzer et al. [19] and Karunarathne et al. [20]. Wu et al. [21] reported that preliminary breakdown pulse characteristics are closely related with initiation altitudes ranges from 5 to $10 \mathrm{~km}$ and preliminary breakdown pulses in negative CG flashes ranges from 4 to $7 \mathrm{~km}$. So the altitude should also be considered when discussing pulse characteristics in IC flashes. Karunarathne et al. [20] and Bitzer et al. [19] demonstrated that PB pulses in IC and -ve CG flashes were produced by negative leaders, and $\mathrm{Wu}$ et al. [22] demonstrated that $\mathrm{PB}$ pulses in +ve CG flashes were also produced by negative leaders. Intracloud lightning flashes are normally starting with upward negative leaders initiated below $10 \mathrm{~km}$ (about $-10^{\circ} \mathrm{C}$ isotherm). Wu et al. [23] recently discovered a special type of IC flash which is initiated at a very high altitude above 12 kilometers (usually above $-50^{\circ} \mathrm{C}$ isotherm) called "downward positive intracloud flash." He found that this downward positive intracloud flash occurs when the initial negative leaders do not propagate upward.

This study aims to investigate the characteristic features of electric field radiated by the subtropical flashes and understand the overall electric discharge process of cloud flashes. The pulses having initial polarity as that of negative return stroke, lowering the negative charge to ground, are termed as negative polarity pulses, and the pulses having opposite polarity to those of negative return stroke are termed as positive polarity pulses. The initial breakdown pulses of the cloud flashes were studied and different features of cloud flashes were compared with those from other geographical regions, especially temperate ones. This is the first time the electric fields radiated by cloud flashes pertinent to the subtropical and mountainous country Nepal were measured, analysed, and compared with those from other geographical regions.

\section{Instrumentation and Measurement}

The lightning generated electric fields were recorded at a measuring station in Kathmandu, Nepal, at $27^{\circ} 44^{\prime} \mathrm{N}$ and $85^{\circ} 19^{\prime} \mathrm{E}$ and about $1300 \mathrm{~m}$ above the sea level. The vertical electric fields of the flashes were sensed by the flat plate antenna fixed on a $1.5 \mathrm{~m}$ high post and were placed on the rooftop of a building at a physical height of about $12 \mathrm{~m}$ from the ground. The upper plate of the parallel-plate antenna was connected to a buffer circuit through a $60 \mathrm{~cm}$ long RG 58 coaxial cable. The signal passing through buffer amplifier was fed to the Pico-scope 6404D through a $20 \mathrm{~m}$ long RG 58 coaxial cable. The signals so received were recorded by the Pico-scope whose window size was $500 \mathrm{~ms}$ at the sampling rate of $1.25 \mathrm{GS} / \mathrm{sec}$. The recording system was similar to what was described previously [24-27]. The zero-to-peak rise time of the antenna system for a step pulse was less than $30 \mathrm{~ns}$. The data have been sampled at $800 \mathrm{ps}$, i.e., at the sampling rate of $1.25 \mathrm{GHz}$ for $200 \mathrm{~ms}$ and $500 \mathrm{~ms}$. The elevated parallel-plate antenna installed in the mountainous region and the electronic circuit pertinent to buffer amplifier is shown in Figures 3(a) and 3(b).

\section{Data and Results}

The electric fields produced by lightning were recorded on different thunderstorm days from March 2015 to September 2017 in the Himalayan region. Of the total record during the campaign, more than three thousand were due to cloud activity, most of them being recorded on April 15, 16, and 17, May 23 and 26, June 12 and 13, July 24, and September 19 of 2015; June 13 of 2016; May 26 and September 17 of 2017. Altogether, only fifty-four cloud flashes have been selected for the analysis in this study. Of those records, some flashes have time window of $200 \mathrm{~ms}$ whereas some have $500 \mathrm{~ms}$ with the sampling rate of $1.25 \mathrm{GS} / \mathrm{sec}$. An example of electric field due to a typical cloud flash having two stages is depicted in Figure 4. It is clearly seen from Figure 4 that the flash consists of initial (or active) stage and final (or late) stage. The fine structures of the large IB pulses with negative initial polarity expanded from IB pulse train are also shown in Figure 5 and expansion of final stage of flash containing fine pulses with both polarities is shown in Figure 6. As is seen, 


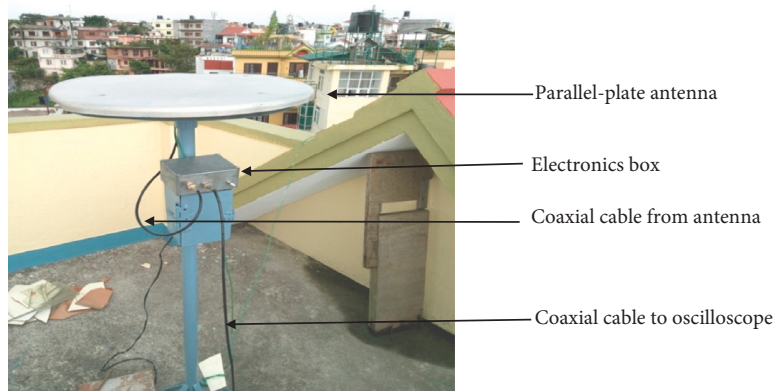

(a)

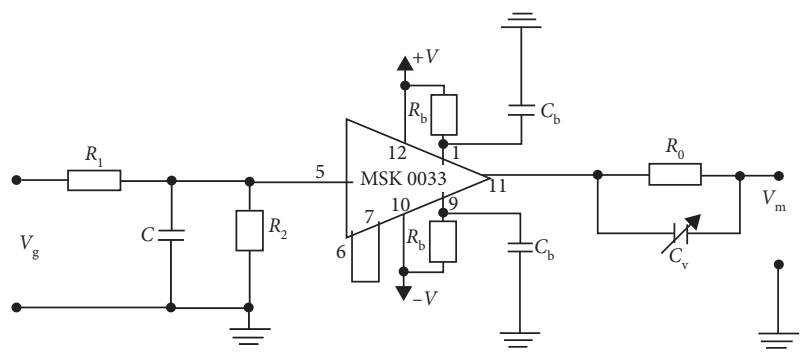

(b)

Figure 3: (a) The elevated parallel-plate antenna installed in Kathmandu and (b) the electronic circuit pertinent to buffer amplifier used in this study.

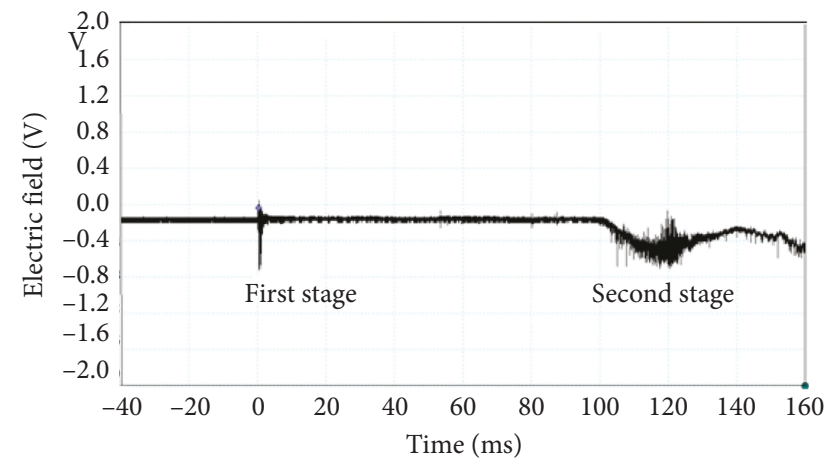

FIGURE 4: An example of the electric field signature of cloud flash consisting of two stages.

small pulses are superimposed in the rising part of the large pulses.

As is seen from Figure 5, the large bipolar pulses pertinent to the active stage have the same initial polarity whereas the pulses in the final stage have both initial polarities, and each individual pulse appears to be of unipolar type. As seen in Figure 4, between the first and second stages, relatively small pulses, possibly hidden by noises in some remote sites, are produced by negative leaders propagating horizontally. Among fifty-four flashes analysed in this study, seven flashes apparently have single stage, forty-six flashes have two stages, and only one flash apparently has three stages. The three-stage flash was recorded on the $500 \mathrm{~ms}$ time window. An example of the electric field due to a typical cloud flash having a single stage is depicted in Figure 7 and having three stages is depicted in Figure 8. The expansions of these three stages of Figure 8, respectively, are shown in Figures 9-11. The average duration for the first stage was $11.23 \mathrm{~ms}$ as compared to $66.79 \mathrm{~ms}$ for the second stage, with a gap of $53.57 \mathrm{~ms}$. The time of activity for the first stage ranged from $3.10 \mathrm{~ms}$ to $19.40 \mathrm{~ms}$, whereas the time of activity for the second stage varied from $18.07 \mathrm{~ms}$ to $130.40 \mathrm{~ms}$. These variations are represented in Table 1.

The first (active) stage of the majority of the flashes was found to consist of large microsecond scale bipolar pulses having negative initial polarity, whereas the late stage consists of submicrosecond scale pulses having both positive and negative initial polarities.

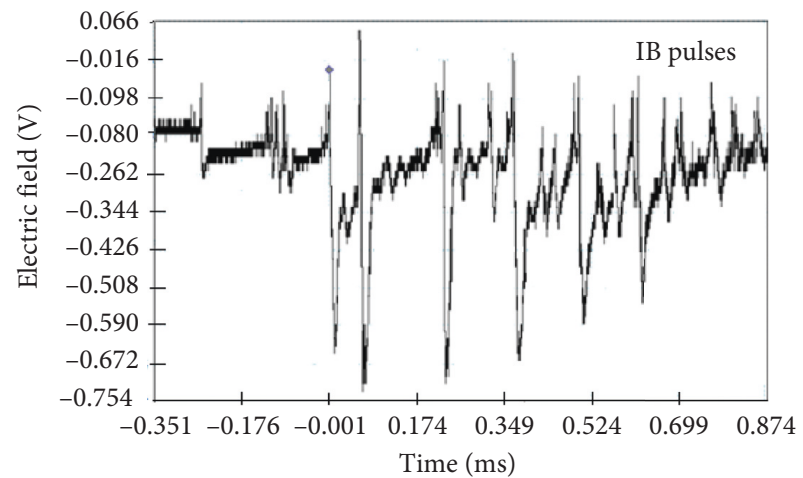

Figure 5: Expansion of initial (or active) stage of flashes from Figure 4 with negative initial polarity.

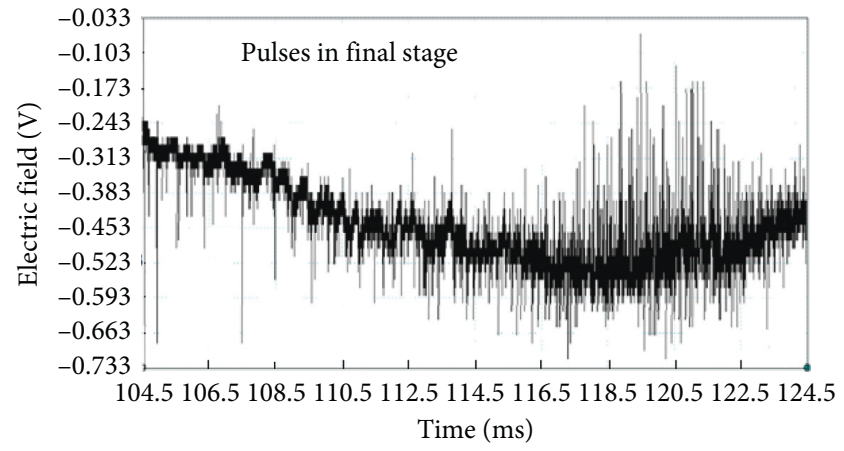

FIGURE 6: Expansion of the final stage of flash containing fine pulses with both polarities.

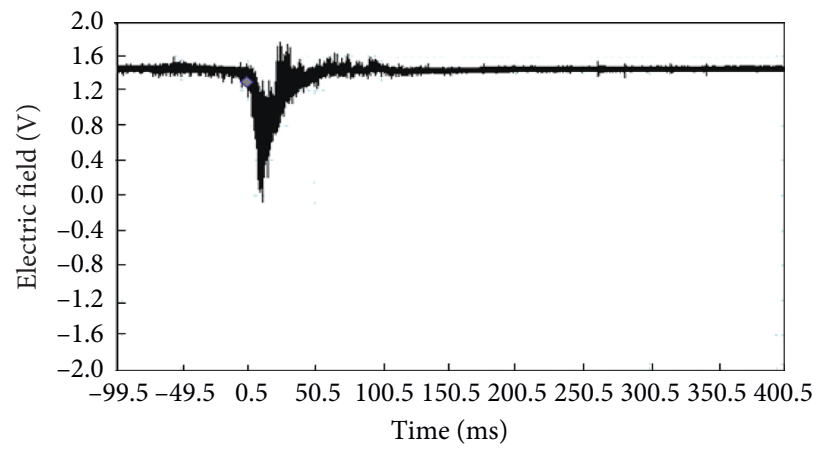

Figure 7: An example of the electric field of a cloud flash that apparently consists of a single stage. 


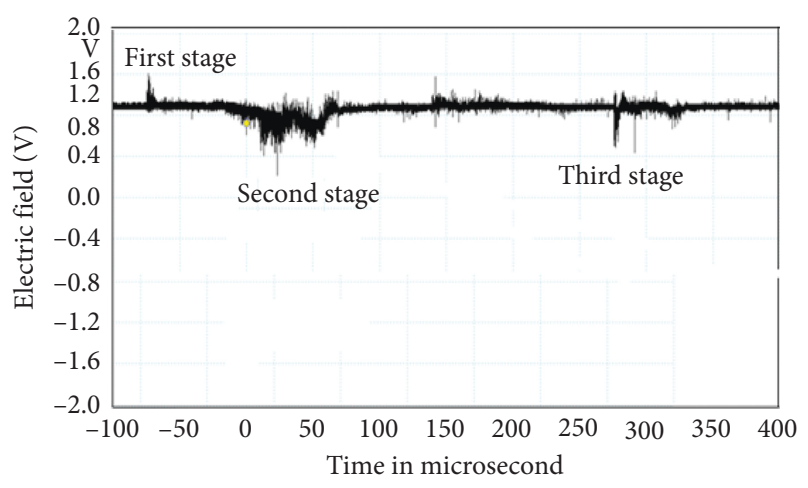

FIgURE 8: An example of the electric field due to a typical cloud flash having three stages.

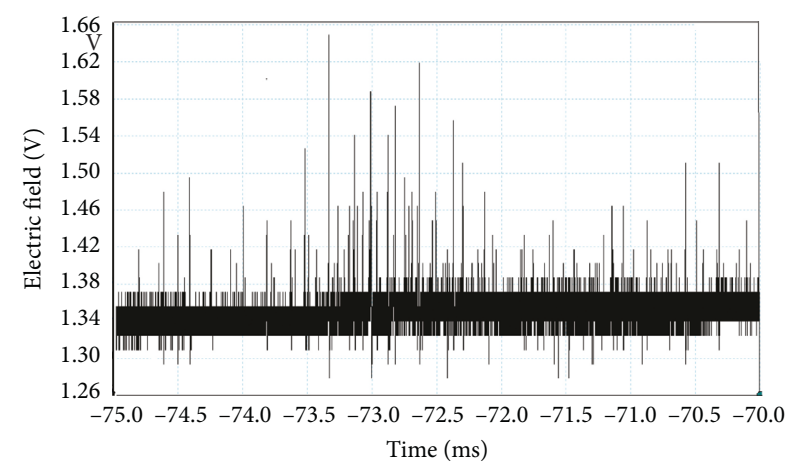

FIgURE 9: An expansion of the first stage of three-stage typical cloud flash of Figure 8.

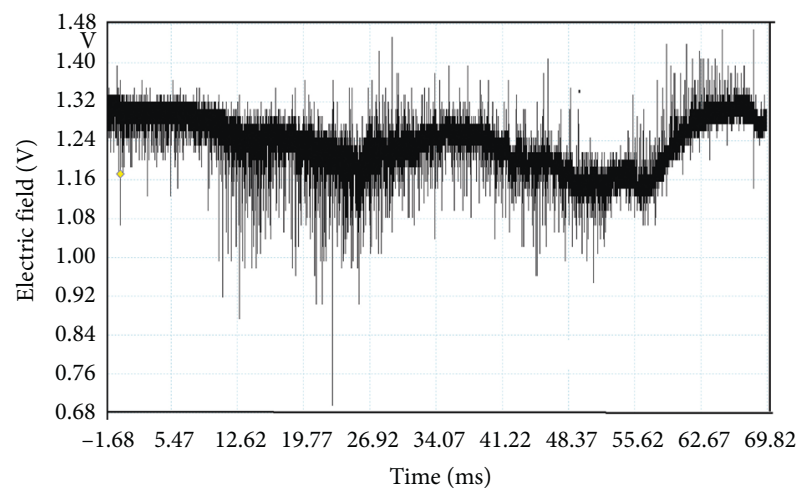

FIGURE 10: An expansion of the second stage of three-stage typical cloud flash of Figure 8.

3.1. For IB Pulses. The occurrence of the breakdown pulses with both polarities suggests that the breakdown apparently takes place either between upper negative charge boundary and positive charge region or between the lower negative charge boundary and lower positive charge pocket. The pulses having initial polarity as that of the negative return stroke, which means lowering the negative charge to the ground, are termed as negative polarity pulses. In this case, the discharges occur between lower negative charge boundary and lower positive charge pocket, which can be regarded as lower-origin and called negative electric field change. Similarly, the pulses having an initial polarity

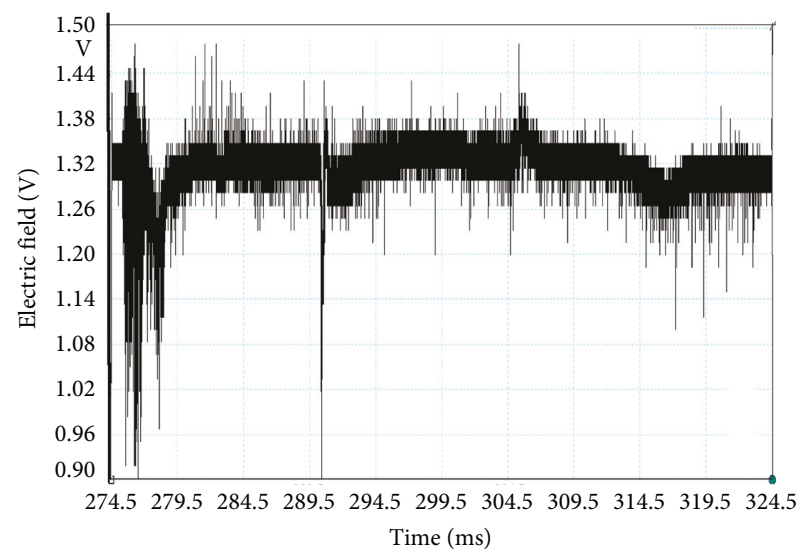

Figure 11: An expansion of the third stage of three-stage typical cloud flash of Figure 8.

opposite to those of negative return stroke, that is, as a positive return stroke, are termed as positive polarity pulses. The discharge between the main negative charge boundary and the upper positive charge region can be regarded as higher-origin cloud flashes and called positive electric field change. In this scenario, the occurrence of the breakdown pulses is one sided, that is, only negative initial polarity occurred. This means that the discharges occur between the main negative charge boundary and the lower positive charge pocket. The maximum peak pulse is on the second position rank whereas the other falls on the $2^{\text {nd }}, 3^{\text {rd }}$, and $4^{\text {th }}$ ranks also. The statistics features of IB pulses are shown in Table 2 below.

3.2. For Cloud Activity. Cloud flashes in this study have been categorized into two types, that is, flashes led by positive initial polarity cloud pulses and those led by negative initial polarity cloud pulses. A summary of the statistics of flashes of both types has been given in Tables 3 and 4 .

The average time of activity led by negative polarity pulses is higher than those led by positive polarity pulses. The time of activity starting from negative field change ranged from $108.6 \mathrm{~ms}$ to $469.5 \mathrm{~ms}$, with an average of $231.1 \mathrm{~ms}$ whereas the time of activity starting from positive field change ranged from $80 \mathrm{~ms}$ to $399.5 \mathrm{~ms}$, with an average of $168.3 \mathrm{~ms}$. Pulses with amplitudes larger than $25 \%$ of the largest pulses in the pulse train have only been considered in this study and pulses with smaller amplitudes than those are not considered for the pulse statistics.

The cloud pulses in the flashes with negative initial polarity are more compactly distributed compared to the positive initial polarity pulses. The interpulse interval between the large pulses has been analysed for each individual flash under consideration, which has then been averaged for each flash. Such average values of interpulse interval have been averaged for all the flashes. The minimum interpulse interval for cloud pulses with positive initial polarity in a flash is found to be as low as $1.33 \mu$ s and the maximum value is found to be as high as $1118 \mu \mathrm{s}$. However, the corresponding values for the cloud pulses with negative initial polarity are found to be $1.07 \mu$ s and 
TABLE 1: Statistics of features of cloud flashes.

\begin{tabular}{lccc}
\hline Statistics of the parameter & Time of activity for the first stage (ms) & Time of activity for the second stage (ms) & $\begin{array}{c}\text { Gap between two } \\
\text { stages (ms) }\end{array}$ \\
\hline Average & 11.23 & 66.79 & 53.57 \\
Max & 19.40 & 130.40 & 117.00 \\
Min & 3.10 & 18.07 & 13.61 \\
Range & 16.30 & 112.33 & 103.39 \\
S. D. & 5.35 & 30.14 & 30.23 \\
\hline
\end{tabular}

TABLE 2: Statistics features of IB pulses.

\begin{tabular}{|c|c|c|c|c|c|c|c|}
\hline Parameters & $\begin{array}{l}\text { Rise times } \\
\quad(\mu \mathrm{s})\end{array}$ & $\begin{array}{c}\text { Total } \\
\text { duration } \\
(\mu \mathrm{s})\end{array}$ & $\begin{array}{c}\text { Time of } \\
\text { overshoot }(\mu \mathrm{s})\end{array}$ & $\begin{array}{c}\text { Duration of } \\
\text { overshoot }(\mu \mathrm{s})\end{array}$ & $\begin{array}{l}\text { Amplitude of } \\
\text { waves }(\mathrm{mV})\end{array}$ & $\begin{array}{c}\text { Amplitude of } \\
\text { overshoot }(\mathrm{mV})\end{array}$ & $\begin{array}{l}\text { IB interpulse } \\
\text { intervals }(\mu \mathrm{s})\end{array}$ \\
\hline Average & 0.93 & 1.90 & 6.29 & 146.63 & 131.03 & 313.76 & 167.41 \\
\hline Maximum & 4.94 & 8.94 & 21.23 & 520.40 & 317.60 & 1416.80 & 731.9 \\
\hline Minimum & 0.10 & 0.38 & 0.65 & 18.40 & 26.60 & 44.80 & 13.57 \\
\hline St. dev. & 0.97 & 1.60 & 4.45 & 99.58 & 56.41 & 236.49 & 116.15 \\
\hline $\begin{array}{l}\text { Coefficient of } \\
\text { variance }\end{array}$ & 1.04 & 0.84 & 0.71 & 0.68 & 0.43 & 0.75 & 0.69 \\
\hline
\end{tabular}

TABLE 3: A summary of the statistics of the flashes with positive initial pulse polarity.

\begin{tabular}{lcccc}
\hline $\begin{array}{l}\text { Statistics of the } \\
\text { parameter }\end{array}$ & $\begin{array}{c}\text { Time of cloud activity } \\
(\mathrm{ms})\end{array}$ & $\begin{array}{c}\text { Interpulse interval } \\
(\mu \mathrm{s})\end{array}$ & $\begin{array}{c}\text { Number of pulses for positive field } \\
\text { change }\end{array}$ & $\begin{array}{c}\text { Number of pulses for negative field } \\
\text { change }\end{array}$ \\
\hline Average & 168.3 & 309.79 & 58 & 38 \\
Max & 399.5 & 1118 & 148 & 142 \\
Min & 80 & 1.33 & 3 & 1 \\
Range & 319.5 & 1116.67 & 145 & 141 \\
S. D. & 66.5 & 290.89 & 45.08 & 41.78 \\
\hline
\end{tabular}

TABLE 4: A summary of statistics for the flashes with negative initial pulse polarity.

\begin{tabular}{lcccc}
\hline $\begin{array}{l}\text { Statistics of the } \\
\text { parameter }\end{array}$ & $\begin{array}{c}\text { Time of cloud activity } \\
(\mathrm{ms})\end{array}$ & $\begin{array}{c}\text { Interpulse interval } \\
(\mu \mathrm{s})\end{array}$ & $\begin{array}{c}\text { Number of pulses for positive field } \\
\text { change }\end{array}$ & $\begin{array}{c}\text { Number of pulses for negative field } \\
\text { change }\end{array}$ \\
\hline Average & 231.1 & 211.42 & 85 & 80 \\
Max & 469.5 & 1110 & 276 & 326 \\
Min & 108.6 & 1.07 & 7 & 6 \\
Range & 360.9 & 1108.93 & 269 & 320 \\
SD & 141.8 & 245.88 & 85 & 90 \\
\hline
\end{tabular}

$1110 \mu \mathrm{s}$, respectively. The average interpulse interval for all the flashes with cloud pulses having positive initial polarity is found to be $309.79 \mu$ s with a standard deviation of $290.89 \mu \mathrm{s}$ and that for the flashes with cloud pulse having negative initial polarity is found to be $211.42 \mu \mathrm{s}$. The fine structure of these largest pulses is similar to those observed by Weidman and Krider [11], Cooray and Lundquist [15], Bils et al. [3], and Medelius et al. [28]. Most of the largest pulses have slow rising and wide bipolar waveforms with several small pulses superimposed on the initial half cycle as seen in Figure 5. However, some of the largest pulses are narrow, singly peaked, and bipolar waveforms in this study.

\section{Discussions and Comparison}

From the analysis, the total duration of the flash varies from as low as $80 \mathrm{~ms}$ to as high as $469.5 \mathrm{~ms}$. Analysing the cloud flashes from the temperate thunderstorm over Sweden, Sharma reported that the total duration of the cloud flash varied from $100 \mathrm{~ms}$ to $400 \mathrm{~ms}$. Those results from temperate country were quite similar to the results found in subtropical and hilly mountainous country Nepal. The average duration of first stage or initial activity is $11.23 \mathrm{~ms}$, which is slightly higher in comparison to those from Sweden that were analysed for below $10 \mathrm{~ms}$. In this study, the duration of the second stage of cloud activity is $66.79 \mathrm{~ms}$ and the average gap between the first and second stages of the cloud activity is $53.57 \mathrm{~ms}$. The average time interval between successive pulses was $309.79 \mu$ s for positive and $211.42 \mu$ s for negative electric field change pulse, which is found to be high as compared to Sharma et al. [29] who determined the average time interval as $35.7 \mu$ s and the average time interval found by Gomes and Cooray [13] was $147 \mu \mathrm{s}$. In the data reported by Weidman and Krider [11], the average time interval 
TABLE 5: A comparative presentation of the features of cloud flashes from various geographical locations.

\begin{tabular}{lccc}
\hline Research carried out by & Average interpulse interval & Duration of activity for the first stage & Duration of cloud flash \\
\hline Gomes and Cooray [13] & $147 \mu \mathrm{s}$ & - & - \\
Sharma et al. [29] & $35.7 \mu \mathrm{s}$ & $10 \mathrm{~ms}$ & $100 \mathrm{~ms}-400 \mathrm{~ms}$ \\
Weidman and Krider [11] & $780 \mu \mathrm{s}$ for negative & - & - \\
& $130 \mu \mathrm{s}$ for positive & $11.23 \mathrm{~ms}$ & $80 \mathrm{~ms}-469.5 \mathrm{~ms}$ \\
Present study & $309.79 \mu$ s for positive & $211.42 \mu$ s for negative &
\end{tabular}

between positive pulses was $130 \mu$ s (less as compared to this study) but for the negative pulses, the time interval is $780 \mu \mathrm{s}$ (high as compared to this study).

Cloud discharges undoubtedly exhibit much variability than ground discharges. This is because the latter involves a relatively well-conducting ground electrode, while cloud discharges are electrodeless [1]. Nevertheless, the majority of the cloud flashes exhibit some features similar to what has been explained by Bils et al. [3] and Villanueva et al. [4]. According to Bils et al. [3] and Villanueva et al. [4], large microsecond pulses produced during the early stage of the flash are likely to be associated with the in-cloud channel formation. The late stage may consist of microsecond scale pulses but with relatively small amplitudes. The occurrence of the breakdown pulses with both polarities suggests us that the breakdown apparently takes place either between upper negative charge boundary and positive charge region or between the lower negative charge boundary and lower positive charge pocket. The discharge between the main negative charge boundary and the upper positive charge region can be regarded as higher-origin cloud flashes and that between lower negative charge boundary and lower positive charge pocket can be regarded as lower-origin as proposed by Proctor [7] and Proctor [8]. It can also be inferred that the breakdown taking place between the lower negative charge boundary and the positive charge pocket, lowering the negative charge towards ground may succeed to culminate into the ground flash or turn into cloud flashes, probably giving rise to the horizontal flashes. Because of the horizontal air discharges, fine electric field discharge is produced throughout the activity. In the high origin flashes, the negative charge propagates towards the upper positive charge region where the charge is extensively distributed horizontally. From Table 5, it can be seen that interpulse interval pertinent to the cloud activity is less in the present study as compared to those of Weidman. This is an indication that the subtropical cloud flashes have the breakdown stage where the discharge occurs in quite a fast succession as compared to those of the tropical ones. Furthermore, because of the distance of the cloud flashes from the measuring station in the tropical region, the electric field due to microdischarges might have undergone the propagation losses whereas over the subtropical and hilly region the flash distance is relatively low and hence does not undergo the significant propagates. Normally, the duration of IC flashes is longer than $500 \mathrm{~ms}$, but here it has a maximum of about $470 \mathrm{~ms}$ since the recording system has a recording length of only $500 \mathrm{~ms}$.

\section{Conclusion}

Electric field radiated by cloud flashes that occurred over the rugged terrain of mountainous country Nepal were recorded and analysed. The features of electric field signatures have been analysed and compared with those from different geographical regions. In this research, the discharges occur between the lower negative charge boundary and the lower positive charge pocket, which can be regarded as lowerorigin. In this study, the discharge between main negative charge boundary and the upper positive charge region, which can be regarded as higher-origin cloud flashes and called positive electric field change and the subtropical cloud flashes have the breakdown stage where the discharge occurs in quite a fast succession as compared to those of the tropical ones.

\section{Data Availability}

The data that support the findings of the study are available from the corresponding author upon reasonable request.

\section{Conflicts of Interest}

The authors declare that they have no conflicts of interest.

\section{Acknowledgments}

First of all, we would like to express our sincere gratitude to the International Science Program (ISP), Uppsala University, Sweden, for providing the instruments necessary for this research. It would not have been possible to carry out this study without their help. Also, we would like to thank Tri-Chandra College, Tribhuvan University. We are also thankful to the Central Department of Physics (CDP), Tribhuvan University, for their support in this research.

\section{References}

[1] V. A. Rakov and M. A. Uman, Lightning: Physics and Effects, Cambridge University Press, New York, NY, USA, 2003.

[2] N. Kitagawa and M. Brook, "A comparison of intracloud and cloud-to-ground lightning discharges," Journal of Geophysical Research, vol. 65, no. 4, pp. 1189-1201, 1960.

[3] J. Bils, E. Thomson, M. Uman, and D. Mackerras, "Electric field pulses in close lightning cloud flashes," Journal of Geophysical Research, vol. 93, no. D12, pp. 933-1015, 1988.

[4] Y. Villanueva, V. A. Rakov, M. A. Uman, and M. Brook, "Microsecond-scale electric field pulses in cloud lightning discharges," Journal of Geophysical Research, vol. 99, no. 14, pp. 353-360, 1994. 
[5] X. M. Shao and P. R. Krehbiel, "The spatial and temporal development of intracloud lightning," Journal of Geophysical Research: Atmospheres, vol. 101, no. D21, pp. 26641-26668, 1996.

[6] W. Rison, R. J. Thomas, P. R. Krehbiel, T. Hamlin, and J. Harlin, "A GPS-based three-dimensional lightning mapping system: initial observations in central New Mexico," Geophysical Research Letters, vol. 26, no. 23, pp. 3573-3576, 1999.

[7] D. E. Proctor, "VHF radio pictures of cloud flashes," Journal of Geophysical Research, vol. 86, no. C5, pp. 4041-4071, 1981.

[8] D. E. Proctor, "Lightning flashes with high origins," Journal of Geophysical Research: Atmospheres, vol. 102, no. D2, pp. 1693-1706, 1997.

[9] C. Gomes, V. Cooray, M. Fernando, R. Montano, and U. Sonnadara, "Characteristics of chaotic pulse trains generated by lightning flashes," Journal of Atmospheric and SolarTerrestrial Physics, vol. 66, no. 18, pp. 1733-1743, 2004.

[10] S. Shriram, Electromagnetic fields radiated by lightning in tropical and temperate regions, Ph.D. thesis, University of Colombo, Colombo, Sri Lanka, 2007.

[11] C. D. Weidman and E. P. Krider, "The radiation field wave forms produced by intracloud lightning discharge processes," Journal of Geophysical Research, vol. 84, no. C6, pp. 31593164, 1979.

[12] E. P. Krider, G. J. Radda, and R. C. Noggle, "Regular radiation field pulses produced by intracloud lightning discharges," Journal of Geophysical Research, vol. 80, no. 27, pp. 3801-3804, 1975.

[13] C. Gomes and V. Cooray, "Characteristics of cloud flashes," in Proceedings of the 14th International Zurich Symposium EMC 58J3, Zürich, Switzerland, February 2001.

[14] D. M. Le Vine, "Sources of the strongest RF radiation from lightning," Journal of Geophysical Research, vol. 85, no. C7, pp. 4091-4095, 1980.

[15] V. Cooray and S. Lundquist, "Characteristics of the radiation fields from lightning in Sri Lanka in the tropics," Journal of Geophysical Research, vol. 90, no. D4, pp. 6099-6109, 1985.

[16] A. Nag and V. Rakov, "Pulse trains that are characteristic of preliminary breakdown in cloud-to-ground lightning but are not followed by return-stroke pulses," Journal of Geophysical Research, vol. 113, no. D19, Article ID D01102, 2008.

[17] A. Nag and V. Rakov, "Some inferences on the role of lower positive charge region in facilitating different types of lightning," Geophysical Research Letters, vol. 36, no. 5, 2009.

[18] A. Nag and V. A. Rakov, "Positive lightning: an overview, new observations, and inferences," Journal of Geophysical Research, Atmospheres, vol. 117, no. D8, 2012.

[19] P. M. Bitzer, H. J. Christian, M. Stewart et al., "Characterization and applications of VLF/LF source locations from lightning using the Huntsville Alabama Marx meter array," Journal of Geophysical Research: Atmospheres, vol. 118, no. 8, pp. 3120-3138, 2013.

[20] S. Karunarathne, T. C. Marshall, M. Stolzenburg et al., "Locating initial breakdown pulses using electric field change network," Journal of Geophysical Research: Atmospheres, vol. 118, no. 13, pp. 7129-7141, 2013.

[21] T. Wu, S. Yoshida, Y. Akiyama, M. Stock, T. Ushio, and Z. Kawasaki, "Preliminary breakdown of intracloud lightning: initiation altitude, propagation speed, pulse train characteristics, and step length estimation," Journal of Geophysical Research: Atmospheres, vol. 120, no. 18, pp. 9071-9086, 2015.

[22] T. Wu, D. Wang, and N. Takagi, "Locating preliminary breakdown pulses in positive cloud-to-ground lightning," Journal of Geophysical Research: Atmospheres, vol. 123, no. 15, pp. 7989-7998, 2018.
[23] T. Wu, D. Wang, and N. Takagi, "Intracloud lightning flashes initiated at high altitudes and dominated by downward positive leaders," Journal of Geophysical Research: Atmospheres, vol. 124, no. 13, pp. 6982-6998, 2019.

[24] P. B. Adhikari, Measurement of Electric Fields Due to Lightning Radiation, Springer Nature Switzerland AG, Basel, Switzerland, 2019.

[25] P. B. Adhikari, "Relation between electric and magnetic fields produced due to lightning discharge," International Journal of Emerging Technologies and Innovative Research, vol. 6, no. 5, pp. 72-77, 2019.

[26] P. B. Adhikari, S. Sharma, and K. Baral, "Features of positive ground flashes observed in Kathmandu Nepal," Journal of Atmospheric and Solar-Terrestrial Physics, vol. 145, pp. 106113, 2016.

[27] P. B. Adhikari, S. Sharma, K. Baral, and V. A. Rakov, "Unusual lightning electric field waveforms observed in Kathmandu, Nepal, and Uppsala, Sweden," Journal of Atmospheric and Solar-Terrestrial Physics, vol. 164, pp. 172-184, 2017.

[28] P. J. Medelius, E. M. Thomson, and J. S. Pierce, "E and dE/dt wave shapes for narrow bipolar pulses in intracloud lightning," in Proceedings of the International Aerospace and Ground Conference on Lightning and Static Electricity, vol. 3106, Fort Worth, Texas, June 1991.

[29] S. R. Sharma, M. Fernando, and C. Gomes, "Signatures of electric field pulses generated by cloud flashes," Journal of Atmospheric and Solar-Terrestrial Physics, vol. 67, no. 4, pp. 413-422, 2005. 


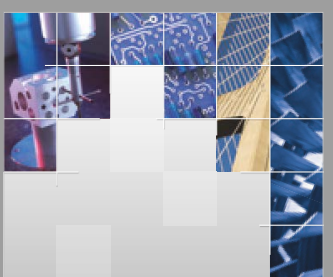

\section{Enfincering}
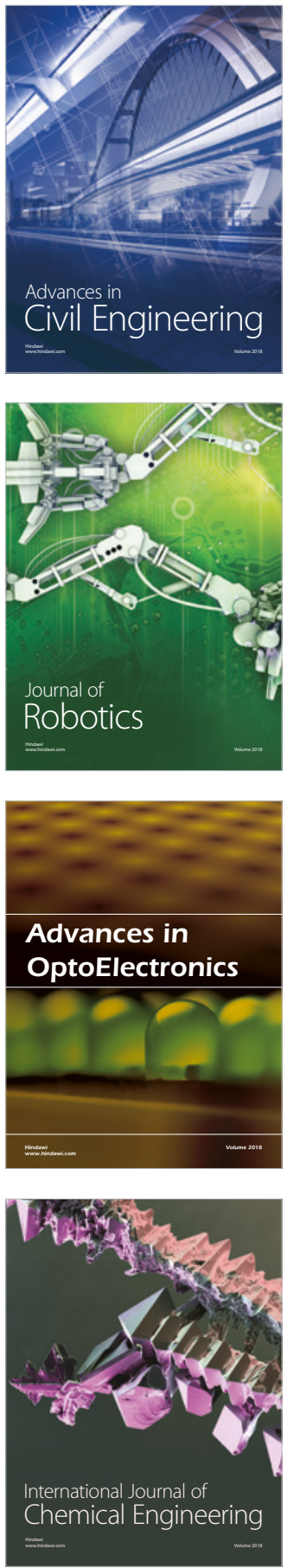

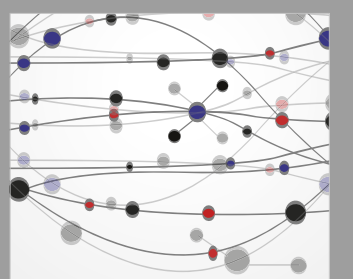

\section{Rotating \\ Machinery}

The Scientific World Journal

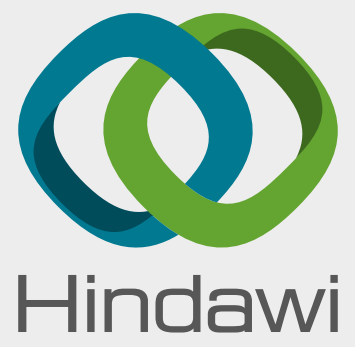

Submit your manuscripts at

www.hindawi.com
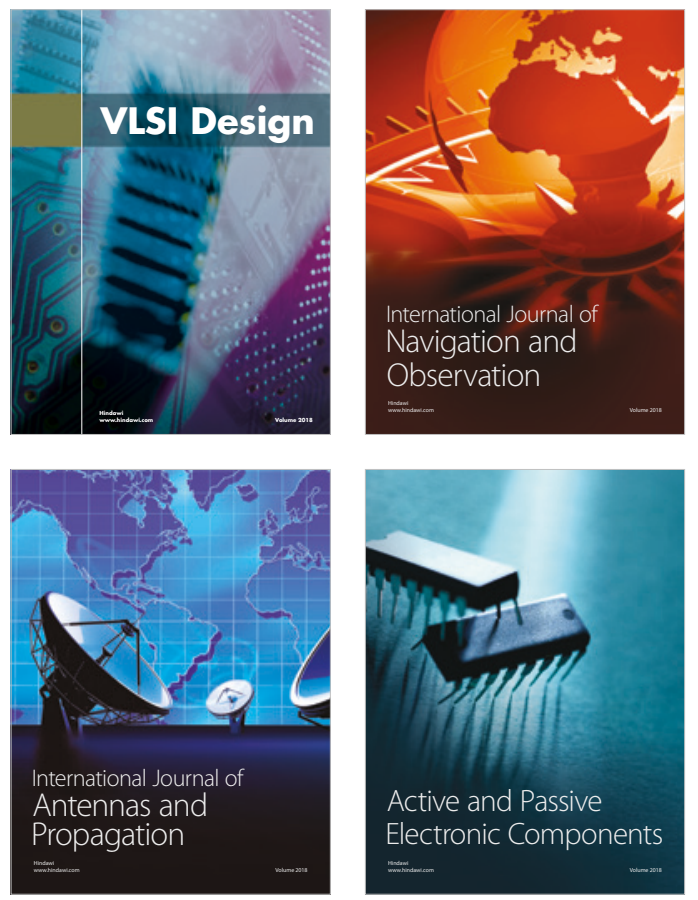
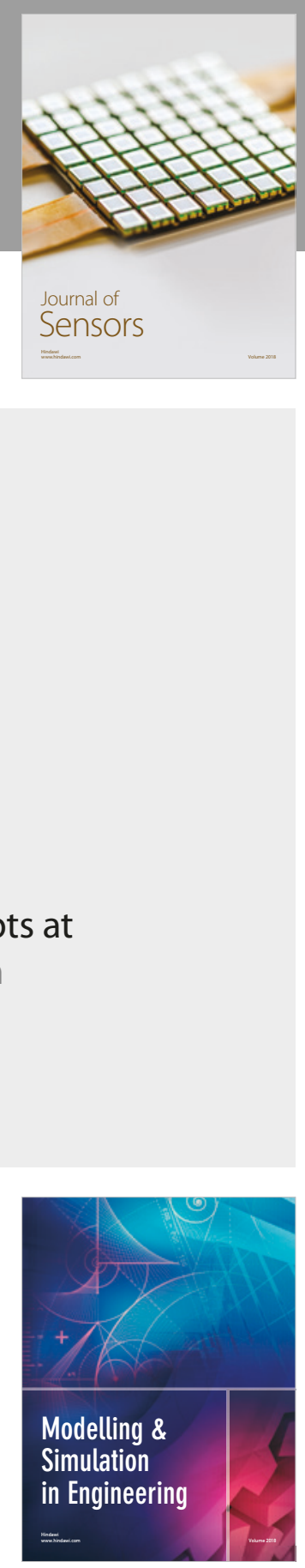

\section{Advances \\ Multimedia}
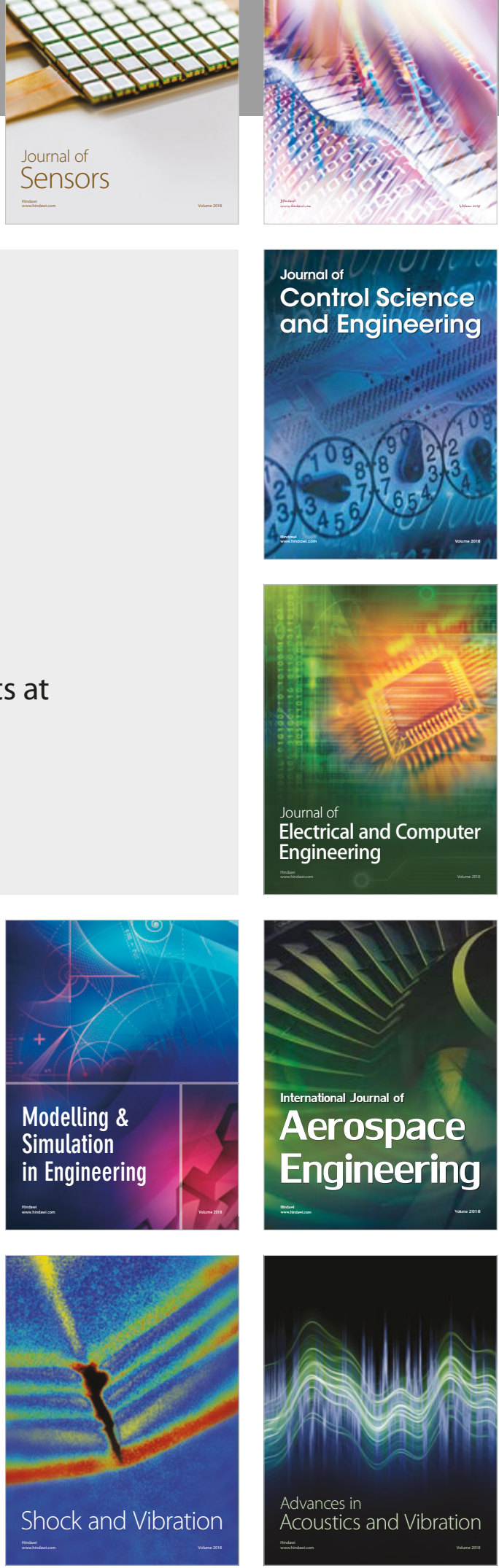